\title{
MOMP Regimen
}

National Cancer Institute

\section{Source}

National Cancer Institute. MOMP Regimen. NCI Thesaurus. Code C161986.

A chemotherapy regimen consisting of mechlorethamine, vincristine, methotrexate, and prednisone that may be used in the treatment of Hodgkin lymphoma $(\mathrm{HL})$. 